\title{
Rotation of the second cervical vertebra in pediatric patient
}

\section{Rotação da segunda vértebra cervical em paciente pediátrico}

\author{
Priscila Dias Peyneauํㅡㄹ Gina Delia Roque-Torres ${ }^{1}$, Luiz Roberto Godolfim ${ }^{2}$, Eliana Dantas da Costa ${ }^{1}$, \\ Solange Maria de Almeida ${ }^{1}$, Gláucia Maria Bovi Ambrosano ${ }^{1}$
}

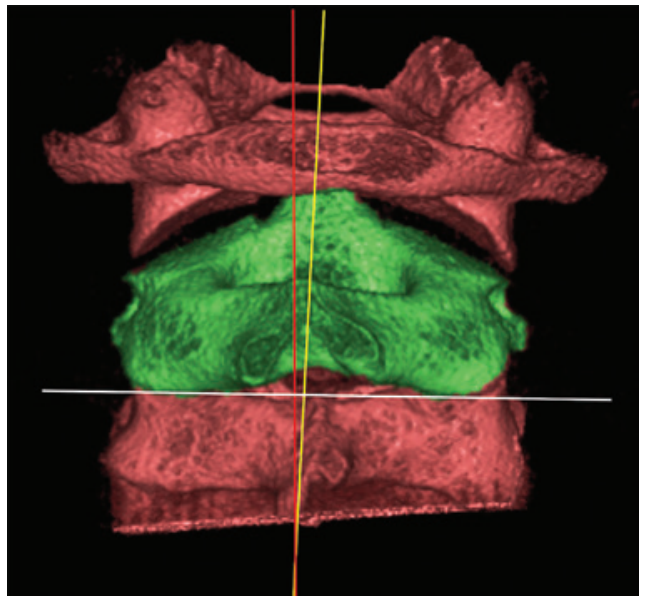

Figure 1. Tridimensional reconstruction of first three cervical vertebrae (posterior view). Rotation of the second cervical vertebra can be observed (green). The yellow line highlights the median sagittal plane; red line represents the rotation of second vertebra; white line indicates latero-lateral inclination of the second vertebra

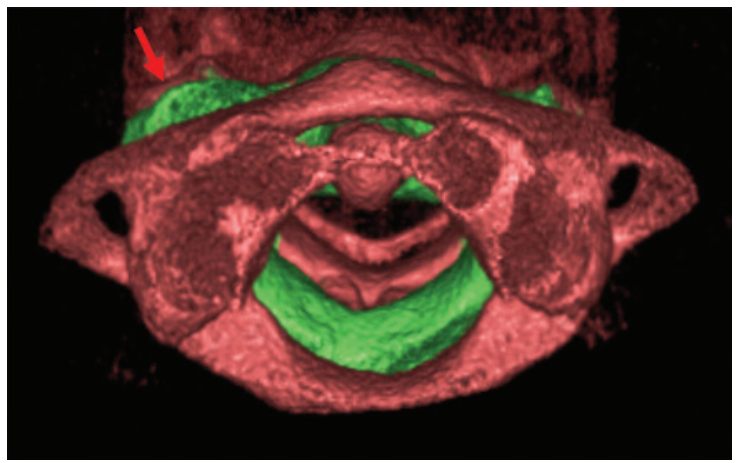

Figure 2. Tridimensional reconstruction of first three cervical vertebrae (transversal view). A rotation of the second vertebra is observed (green). Red arrow indicates the rotation of the second vertebra

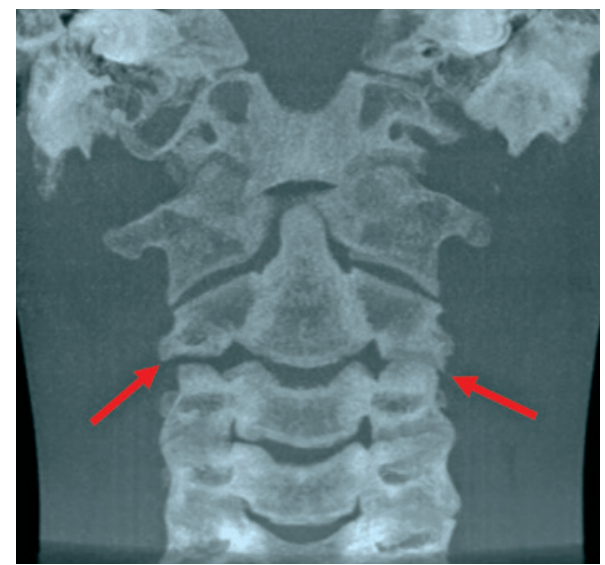

Figure 3. Coronal reconstruction of cervical vertebrae. Red arrows indicating latero-lateral inclination of the second vertebra

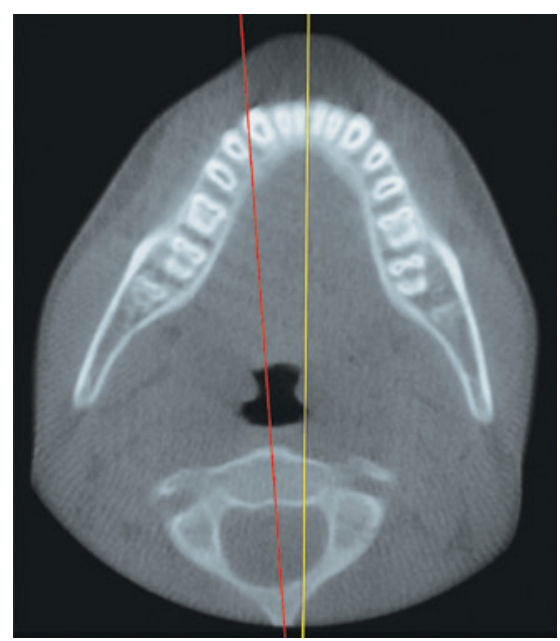

Figure 4. Axial reconstruction. Yellow line showing medium sagittal plan; Red line indicating rotation of the second cervical vertebra

\footnotetext{
' Faculdade de Odontologia de Piracicaba, Universidade Estadual de Campinas, Piracicaba, SP, Brazil.

2 Universidade Federal do Rio Grande do Sul, Porto Alegre, RS, Brazil.

Corresponding author: Eliana Dantas da Costa - Avenida Limeira, 901 - Areãao - Zip Code: $13414-903$ - Piracicaba, SP, Brazil - Phone: (55 19) 2106-5327 - E-mail: elianusp@yahoo.com.br Received on: Feb 1, 2016 - Accepted on: Apr 12, 2016

DOI: 10.1590/S1679-45082016Al3631
} 

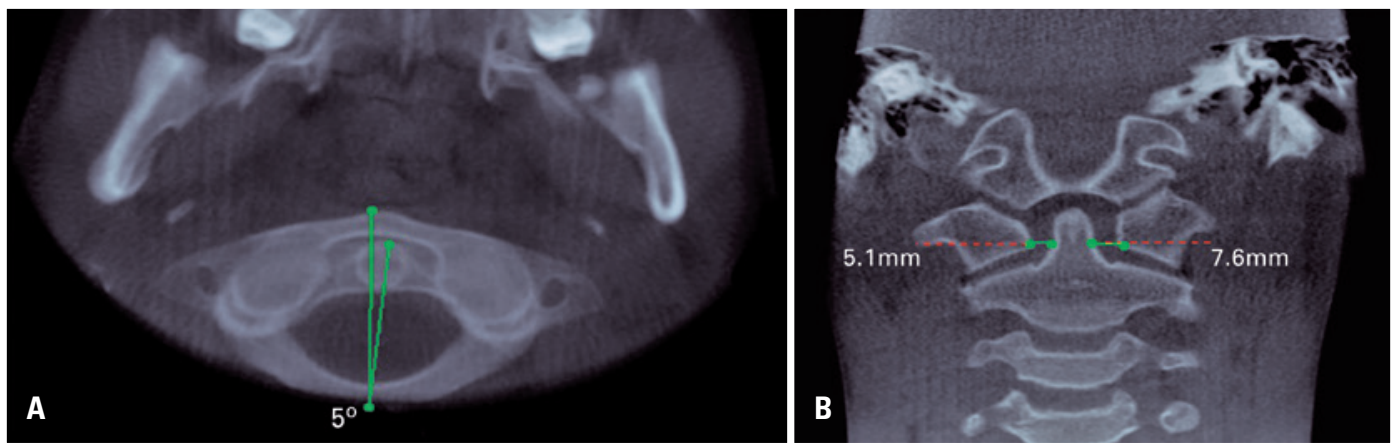

Figure 5. Cone beam computed tomography showing $5^{\circ}$ of axial rotation in relation to medium line (A), atlanto-axil space of 5.1 and $7.6 \mathrm{~mm}(B)$

Rotatory instability is characterized by the rotation between two vertebral bodies, and it constitutes the most common cause of torticollis in children. ${ }^{(1-5)}$ This prevalence occurs because of specific anatomic characteristics of childhood, such as disproportion between head-neck, underdeveloped cervical musculature, laxity of the joint capsule, ligament elasticity and horizontal shape of the articular facets between atlas and axis vertebrae..$^{(3-7)}$ This condition can occur due to inflammation/infection ${ }^{(2,6,7)}$ or trauma, ${ }^{(1,2,4,6)}$ or because of neurogenic or idiopathic origin. ${ }^{(2)}$

The diagnosis includes clinical and imaging exam..$^{(7,8)}$ Among imaging exams of bone tissue, radiographies in anteroposterior and lateral projections are of limited use because they do not enable a precise visualization of this alteration, due to difficulties in positioning patients (head offset or source of X-rays, and overlap of structures), leading to radiographic interpretation challenges. ${ }^{(1,6,7)}$ Computed tomography is considered the gold standard procedure. ${ }^{(1,6,7)}$ Images of tridimensional reconstruction provides a global visualization of rotation, therefore helping to establish the diagnosis. ${ }^{(2,3,7)}$ In addition, the magnetic resonance image can also be requested to evaluate the risk of vascular-nervous bundle compromising and injuries of the ligaments adjacent to vertebrae. . $^{(1,5-7)}$

A 12-year-old boy was referred to our radiologic clinic to undergo a cone beam computed tomography for orthodontic purposes. We carried out a tridimensional, axial, coronal and sagittal reconstruction (Figures 1 to 5). During imaging assessment, we observed $5^{\circ}$ of rotation of the second cervical vertebra in relation to medium line and a space between atlanto-axial vertebrae of
5.1 $\mathrm{mm}$ (right side) and 7.6mm (left side) (Figure 5). In anamnesis, the patient reported trauma experienced 1 year earlier and, after the incident, presence of constant torticollis.

Correct diagnosis is crucial for adequate management. Treatment can be conservative using immobilization, ${ }^{(3-5,7,9)}$ traction or manual reduction, ${ }^{(3,4,7,9)}$ with the use of analgesic, ${ }^{(3)}$ physiotherapy ${ }^{(1,9)}$ or surgery. ${ }^{(3,7,9)}$

\section{REFERENCES}

1. Gradl G, Maier-Bosse T, Penning R, Stäbler A. Quantification of C2 cervical spine rotatory fixation by X-ray, MRI and CT. Eur Radiol. 2005;15(2):376-82.

2. Tachibana A, Imabayashi $H$, Yato $Y$, Nakamichi $K$, Asazuma T, Nemoto K. Torticollis of a specific C1 dislocation with split atlas. Spine (Phila Pa 1976). 2010;35(14):E672-5.

3. Meza Escobar LE, Osterhoff G, Ossendorf C, Wanner GA, Simmen HP, Werner CM. Traumatic atlantoaxial rotatory subluxation in an adolescent: a case report. J Med Case Rep. 2012;6:27.

4. Min Han Z, Nagao N, Sakakibara T, Akeda K, Matsubara T, Sudo A, et al Adult traumatic atlantoaxial rotatory fixation: a case report. Case Rep Orthop. 2014;2014:593621.

5. Missori P, Marruzzo D, Peschillo S, Domenicucci M. Clinical remarks on acute post-traumatic atlanto-axial rotatory subluxation in pediatric-aged patients. World Neurosurg. 2014;82(5):e645-8.

6. Maida G, Marcati E, Sarubbo S. Posttraumatic atlantoaxial rotatory dislocation in a healthy adult patient: a case report and review of the literature. Case Rep Orthop. 2012;2012:183581.

7. Bellil M, Hadhri K, Sridi M, Kooli M. Traumatic atlantoaxial rotatory fixation associated with C2 articular facet fracture in adult patient: case report. $J$ Craniovertebr Junction Spine. 2014;5(4):163-6.

8. Mönckeberg JE, Tomé CV, Matías A, Alonso A, Vásquez J, Zubieta JL. CT scan study of atlantoaxial rotatory mobility in asymptomatic adult subjects: a basis for better understanding C1-C2 rotatory fixation and subluxation. Spine (Phila Pa 1976). 2009;34(12):1292-5.

9. Fuentes S, Bouillot P, Palombi O, Ducolombier A, Desgeorges M. Traumatic atlantoaxial rotatory dislocation with odontoid fracture: case report and review. Spine (Phila Pa 1976). 2001;26(7):830-4. 